\title{
The Three Levels of Education in Site Design Course of Architecture
}

\author{
Yuanyuan Shi* \\ Shandong University of Art \& Design, Jinan 250014, China
}

\begin{abstract}
Professional Guiding Standards for Advanced Education Architecture in University Undergraduate Students" (2013 edition) indicates that the education system of architecture should include a section on "environment and site." It should involve six learning components which are concepts of site and environment, site terrain classifications, environment of two tendencies, elements involved in the sites, elements of environmental impact, and site design. ${ }^{[1]}$ As site design (drawing) has become a significant topic in the examination of registered architects, many domestic architecture colleges have set up site design courses as independent ones. After more than ten years of exploration and research in developing the education system of site design courses, teaching experiences and achievements have been acquired. Site design courses have been gradually integrated with general plan design, registered architect examination, and architectural programming. Teachers have specified relevant learning goals in the regular daily curriculum in addition to the basic and vocational education of architecture. In this way, the site design course would be more in line with the educational goals of architecture. This paper aims to analyze the education of site design courses in hope of developing the future architectural education.
\end{abstract}

Keywords: Site design; General plan; Architect registration examination; Architectural programming

Publication date: May, 2021; Publication online: 31 May, 2021

*Corresponding author: Shi Yuanyuan, 160241@sdada.edu.cn

\section{Introduction}

Site design is a series of activities which is based on the current situation of groundworks, laws, and regulations in designing and organizing the use of different elements in the construction site to meet the requirements of a construction project. ${ }^{[2]}$ In the development process of construction projects, site design involves the whole process of urban and rural planning, landscape designs, architectural designs, as well as engineering constructions. The site design course covers a wide range of activities and contents. Generally, it is related to the plan of a project, while more specifically, it is associated with the fine control of environmental surroundings. All the above mentioned are under the category of site design. For architects, site design is compulsory and is an essential professional skill. Research, analysis, and utilization of site conditions are often the source of inspiration for architectural design. Site design, which determines the direction of a design scheme is a breakthrough for successful architectural designs.

However, for a long time, no such course exists in China's education system for undergraduate students majoring in architecture. The content taught in the site design course is covered in architectural design. Its patterns rely on the architectural design scheme to be presented and expressed. With the expansion in education research and the complexity of architectural design projects, there is an urgency and necessity to learn relevant knowledge of site design specifically. Hence, at the beginning of this century, many architectural departments in China had the idea of setting up site design as an independent course. By establishing this course independently, the importance of site design is emphasized, the connection between site design and other professional courses is strengthened, and the integration of architecture and planning, landscape 
and other related disciplines is enhanced. It helps students to establish a systematic knowledge structure while cultivating their abilities for overall organization, general thinking, and comprehensive designing. After more than ten years of exploration and practice, the education department in China have gradually gained achievements and experiences in terms of curriculum content, teaching methods, and effects. This paper takes into account of architectural design education and the prospects of future development in site design courses.

When China had initially developed the site design course, the systematic organization of its lessons was unclear. It is understood that site design courses are complicated. It involves a wide range of fields including topics like society, economy, culture, technology, aesthetics, and others. This raised questions in terms of establishing the structure of the theoretical framework of the course, balancing the relationship between theoretical knowledge and practice, as well as allocating reasonable learning hours. These questions need to be answered in a step-by-step practical teaching process.

The method to carry out site design work in China is based on a collection of effective design experiences which are obtained from previous practices as there are insufficient research. At present, the teaching materials that are used in colleges and universities for site design courses focus on explaining the basic concepts, constraints, work points, creative skills of site design, and to enumerate the design examples for analysis and commenting. If the arrangements of lessons are simply organized based on the contents in textbooks, it is inevitable that the students will just passively listen in the classroom. Hence, the students' understanding towards site design will be based only on textbook knowledge and it will be difficult for them to form actual learning experiences in designing. In addition to that, the topics of general layout, site design condition analysis, traffic organization, vertical layout, pipeline synthesis, greening and environmental landscape layout are divided into several chapters, which weakens the mutual constraints between the comprehensiveness of site design and various site elements. This is then quite different from the requirements in actual site design work.

It would be more efficient for students to learn with questions. By providing design topics for them, students will be the ones to analyze the situation of the basement, design the requirements of the task book, and attempt to seek solutions independently. This will encourage their enthusiasm in learning. However, the emphasis of site design varies, and different propositional methods convey different teaching directions. In the recent years, the educational practice of site design courses which is based on experience only has gradually moved to more scientific and professional development. This is in line with the advanced international teaching concept and architectural design concept.

\section{First Level in the Education of Site Design Course - Integrating General Plan Design}

For undergraduate students majoring in architecture, architectural design course is the core of the education plan in the whole education process. In architectural design, students usually neglect site factors. In short, they do not take note of environmental factors while devoting their time and energy to the design of architectural monomer. They neglect the full consideration and expression of the site, environment, and general plan while focusing on the organization of architectural functions, the composition of architectural forms, and the layout of architectural structures. This shows that they do not place importance to the design of architectural sites. Site design is a comprehensive subject which involves the analysis of fundamental construction case, site layout, traffic organization, vertical design, pipeline synthesis, environmental protection, landscape construction, analysis of economic conditions, and many more elements. It would be difficult to consider all those in carrying out the designing work. With limited class hours, students will not be able to grasp all these aspects. Hence, the time and energy devoted to site designs are minimal which affects the design depth of the site. 
In architectural design courses, after the completion of the whole architectural design plan, students will integrate the outline of the building with the shape of the land. They would include the necessary elements like roads, parking, greening, and others around the building. They will then draw a general plan to meet the project's technical requirements. Students' willingness and understanding of site design are not profound. They assume that the ability to attract audience's attention is the best way to evaluate the success of a project. These attitudes lead to design inconsistency while site design simply becomes a drawing contest. When architectural students graduate and step into the workforce, these are reflected in their architectural design work, whereby the buildings and construction materials are exquisite in form, but the surroundings of site are simple and roughly done. These students are only able to propose planting of greeneries around the buildings which results in a disunified appearance of the city and living environment. It is acknowledged that some architectural design projects are problematic because of unreasonable site design and its effect on the layout of urban planning.

Initially when site design became an independent course, one of its purpose was for students to place importance to the design of a general plan. Through the learning of site design, students may have a comprehensive understanding of site design and its constraints, understand the constraints on each level, and familiarize with each concept and its contents. In this way, students may flexibly apply site design skills and methods to solve practical problems. The course adopts the propositional method of reviewing the general plan in architectural design. This helps students to use the knowledge of site design in dealing with the relationship between buildings and urban planning, appropriately arranging the entrance and exit of buildings, planning the traffic flow in the site, and trying to make as few mistakes as possible. Through this course, students will also be able to emphasize on the design of site environment and set up the consciousness of landscape design.
Hence, the perception that a building project is not only a simple architectural ontology design, but also contains meticulous environmental design will be well understood. The contents of architectural design, planning, and landscape should be embodied in the general plan. They should also be rigorously, meticulously, and vividly expressed to conform to the complexity of general plan designs.

\section{Second Level in the Education of Site Design Course - Integrating the Registered Architect Examination}

By having an independent site design course, the students' ability of general plan design and expression may be improved. However, there are some issues to this. For example, students may regard site design as merely drawing a general plan while neglecting the constraints of the design specifications standards. They would also focus only on composition and formal language, as well as pursuing artistry and innovation. In addition to that, examples of design sites are usually virtual ones which are created by the educator's imagination. These examples generally portray surrounding environments which are simple and idealized. The complex constraints in actual projects are not considered which leads to the students' shortfall in solving practical problems. These problems are reflected in the architectural design curriculum which urge educators to continually contemplate about its curriculum.

With the development of site design courses, many more architectural colleges have been conducting them. The combination of architectural education with vocational education has been the objective in consideration of the professional future development of architectural students and the implementation of the registered architect system in China. Since 1994, China has conducted the first class registered architect examination. In this examination, site design (drawing) is one of the most important yet challenging topics. Architectural graduates who are determined to engage in the architectural career must face the reality that this examination is a necessity. In view of that, many architectural departments integrated 
the registered architect examination site design projects into their courses. The introduction of the examination contents will guide students to be more pragmatic in regard to site design, master its specifications and techniques, as well as to adapt quickly to the professional work requirements of architectural designers in the future.

This kind of teaching arrangements enriches the curriculum structure of the general plan design in the early stage and helps to make the site design practical. For example, the challenges in site analysis are helpful for students to determine the scope of construction in a project base and to reasonably construct the layout of buildings in the general plan. In regard to site profile and terrain design, they are helpful for students to master the complexity of topographic map, promote the students' design ideas, and put forward a more local and regional architectural design scheme. ${ }^{[3]}$ Learning and analyzing the challenges in the examination of registered architects may help students in regard to their professional skills. The integration of the teaching contents with reference inspection and on-site education may promote the students' perceptual understanding. Hence, by merging the design requirements, site drawings, and actual results, encourages students to form a sense of space and scale in the knowledge of site design.

Modern architectural design works are systematic industrial projects which involve many professionals. Architects and engineers of various specialties are required to cooperate and work together. The refinement and specialization of design have become increasingly prominent whereby site design has its own professional requirements and cooperation with other specialties. Hence, architects are required to have strong skills for site design, master the relevant professional skills, and to deal closely with other specialties which are responsible for structure development, equipment, and so on in order to smoothen the construction process. This is the reason why it is necessary to practice similar targeted topics in educational courses.

Of course, the site design course is not a training platform for the registered examination. Undergraduate students are not architectural design practitioners yet, so in the process of education, the conscious control of trivial and redundant specifications as well as complex engineering calculations need to be reconsidered. The focus should be on factors that will greatly influence the architectural design plan. The main goal of the course is to develop students' logical thinking which will benefit students in establishing the consciousness of site design and preserving their development space for more creative thinking. Site design does not only involve technical designs, but it also concerns the spirit, culture, and aesthetic aspects as well. These links are easily neglected in the teaching process. Therefore, emphasis should be on the integration of technology and artistry of site design to improve students' comprehensive qualities. The course should retain the corresponding lessons in regard to the registration examination so that students can master the necessary professional skills. In addition to that, people's behavior, psychology, and aesthetic requirements should also be emphasized to increase the humanistic care in relation to site design. In simple terms, the training of site design born out of the registration examination should not only be restricted to the requirements of the examination. Therefore, shaping this kind of site design education for sustainable development should be taken as a serious responsibility.

\section{Third Level in the Education of Site Design Course - Integrating Architectural Planning}

A construction project needs to go through several stages such as project establishment, design, and construction before it can be completed. Whether the results of the project will meet the usage requirements or the benefits of land development and utilization, it will take several years after completion to deliver a convincing answer. The construction market of China is fast and has large construction scales. In view of active development in the urban and rural areas, there is a tendency that people would exploit imprudently by completing the design work without enough consideration. For 
example, in the process of construction, the development potential of the land is neglected, the benefit of the land usage is low, or the volume ratio is too high, and the intensity of land usage is beyond the reasonable range. There are times when buildings are developed only in consideration of convenience and the economic factor. This would result in a negative effect on the city's functions. In addition, with the development of urbanization that is moving into a new age, many development projects are no longer new projects only. In many cases, old buildings require transformation, and the environment of the existing buildings need to be upgraded. Hence, the subject of site design is gradually diversified. These issues are closely related to site design, but they are beyond the present scope of this subject.

Site design is the initial step in architectural design and is inextricably linked with architectural planning. To avoid purposeless development and resources wastage, architects should have the skills and consciousness in architectural planning. They should systematically evaluate the rationality of the project task book and provide professional suggestions in the construction process. The target scales, external and internal conditions, concepts of space, and other aspects of the building planning will affect and determine the results of site design. If site designs are not guided by architectural planning, there will be risk of deviations which leads to unwarranted projects being constructed. At present, the local and abroad architectural design industry have reached a consensus that the development of the industry should be based on architectural planning and guidance of architectural design. This leads to the assertion of corresponding requirements for architectural design education.

Although architecture is a technical carrier, it also carries the civilized achievements of human social development. Specifically, in terms of site design, previous teachings have focused on the "hardware" while neglecting the "software" of the site itself such as the spiritual as well as the local context of the place, aesthetic attributes, and so on. These are essential components of architectural planning which supplement the site design education deficiencies. It is an immemorial mission of contemporary architects to emphasize on local architectural traditions and cultural heritage by integrating site designs with local cultures. This is to retain the historical value of cities and villages, integrate local characteristics into new creation of architectural works, and nurture a sense of belonging.

All along, site design courses have been guiding students to plan and build reasonable projects according to the projects' foundation. Students have been taught to flexibly use terrain to design vivid buildings while considering the environmental design as the base. Emphasis has been placed on training the students' ability to analyze task books and to create beautiful landscape forms. However, with the rapid development of the construction industry today, the country and society view construction projects in a more rational manner and they are pursuing the concept of "applicable, economic, green, and beautiful" buildings. Therefore, while cultivating students' skills, the concept of Tao should also be introduced. The common goal of site design is to create high quality architectural works. To achieve that, it requires a broader perspective whereby architectural design should be taken into consideration more systematically. Site design is a very practical course and there is a need to introduce actual designing projects as training. It will be helpful for students to understand the construction requirements, complexity, and importance of site designs. The introduction of architectural planning into the site design course is an inevitable requirement of basic education in architectural design.

Site design is a relatively "new" course in the undergraduate architecture education system in China. The teaching experiences are limited to a certain degree whereby feedbacks are still needed so that the course can be better integrated into the professional architecture educational system. Site design is based on cultivating students' holistic way of thinking to establish the complementary relationship between the site, environment, architecture, city, and landscape. After years of 
practice, the current site design courses are able to help students to be more skillful in general plan design, understand the relationship between site and architecture, and acknowledge the relevant requirements for the registered architect examination. Educators have also been introducing the concept of architectural planning in site design courses as well. In this way, students will be more equipped with a stronger sense of responsibility towards the society. They would not blatantly design a project, but would apply professional knowledge to establish more systematic, reasonable, and appropriate work in enhancing the comprehensive benefits and cultural heritage of buildings.

In relation to educational targets and development directions of site design courses, its contents can be further enriched. In addition to the necessary theoretical knowledge of site design, more practical topics should be introduced to guide students in experiencing the whole process of data collection, project planning, design task drawing, and site design especially in the early stage of the project. The students' perception that site design drawing is an isolated category needs to be changed. A visit to the completed construction project site should also be arranged if time allows. Opportunities through observation, random interviews, and other forms of self-experiences will provide a platform for students to note the advantages and disadvantages of project site designs. By integrating the theory, design drawings, and field experiences, they will be able to appreciate the work content of site designs and understand their important impacts. Other than that, students can be divided to form design groups, simulate the patterns in architectural design work, and brainstorm to solve problems pertaining site designs. In this way, they will gain adequate knowledge which covers a wide range of topics, hence, avoiding the omission of important points.

In line with the increasing complexity of contemporary building development projects, the registered architect examination is also adjusting accordingly. In complete construction projects, site design is essential, and its success or failure has great influence. There is a need for continual development of site design courses and constant improvement among its educators.

\section{Disclosure statement}

The author declares no conflict of interest.

\section{References}

[1] Wang, W(2018). Research on Teaching Reform of Site Design based on the Joint training Model of $\mathrm{A}+\mathrm{U}+\mathrm{L}$ three majors. A\&C Theory Research, 12.

[2]Zeng, H., Xie, J(2018). Application-based "Site Design” Teaching Inquiry. Knowledge Library, 11. [3] Yu, M., Zhang, N., Liu, R., Xu, D., Zhang, L., Li, Y., Han, W(2020). Research on Teaching Optimization of site Design course based on Applied Talent training. Education Modernization, 6.

[4] Li, W., Li, M(2019). Teaching Method and Thinking of "Site Design" Course in Architecture. Education and Teaching Forum, 8.

[5]Zhao, Y(2018). Teaching Reform and Reflections on "Site Design" Course in Architecture. New Curriculum Research, 2. 